\title{
An Assessment of Mental Wellbeing and Health-Related Quality of Life Among Youth Living in Central Mexico
}

\author{
Steven Hoffman ${ }^{1}$, Heidi Adams Rueda ${ }^{2} \&$ Stefan Chase $^{1}$ \\ ${ }^{1}$ School of Social Work, Brigham Young University, Provo, Utah, USA \\ ${ }^{2}$ Department of Social Work, University of Texas at San Antonio, San Antonio, Texas, USA \\ Correspondence: Steven Hoffman, School of Social Work, Brigham Young University, Provo, Utah, 84602, 2167 \\ JFSB, USA. Tel: 1-801-422-3211. E-mail: steven_hoffman@byu.edu
}

Received: December 11, 2019 Accepted: January 25, 2020 Online Published: February 6, 2020

doi:10.5539/gjhs.v12n3p1

URL: https://doi.org/10.5539/gjhs.v12n3p1

\begin{abstract}
The current state of adolescent mental health and wellbeing in Mexico constitutes a serious public health concern. In an effort to better understand the potential impact this crisis is having on youth in Central Mexico, we designed a study to assess the connection between Mental Wellbeing and Health-related Quality of Life among a sample of children in junior high school. Descriptive statistics suggest that $22.5 \%$ of our sample was "at-risk" of poor health-related quality of life, with $19.8 \%$ at risk within the physical subscale and $24.3 \%$ at risk within the psychosocial subscale. Regression analyses showed that mental wellbeing scores significantly predicted scores on the physical subscale of the quality of life measure, but did not predict overall wellbeing or psychosocial wellbeing. If replicated, our results may have important implications for health professionals, social workers, researchers, policy makers, and other individuals living in Mexico. We encourage continued research among Mexican youth in rural, underserved areas of Central Mexico such as Michoacán in order to further support strengths-based approaches for improving both their mental wellbeing and quality of life.
\end{abstract}

Keywords: mental wellbeing, quality of life, Mexico, youth, adolescence

\section{Introduction}

\subsection{Mental Health in Mexico}

Estimates within the last decade indicate that $10-20 \%$ of youth throughout the world struggle with mental health issues (Kieling et al., 2011). While this is a global issue, one country that appears to be faring worse than others is Mexico, which is estimated to have twice the prevalence of mental disorders among children and adolescents compared to neighboring countries like the U.S. and Canada (Espinola-Nadurille, Huicochea, Raviola, Ramirez-Bermudez, Kutcher, 2010; Perkins, Wood, Varjas, Vanegas, 2016). Unlike wealthier countries, however, youth struggling with mental health challenges in Mexico face the disheartening prospect of a severely underfunded mental health network with inadequate providers (Organisation for Economic Cooperation and Development [OECD], 2012; Perkins, Wood, Varjas, \& Vanegas, 2016). This incomplete system is likely leaving thousands of youth captive to a lifetime of potentially preventable mental health problems (Albores-Gallo, Sauceda-García, Ruiz-Velasco, \& Roque-Santiago, 2011; Borges, Wang, Medina-Mora, \& Chiu, 2007; Kieling et al., 2011).

Various ideas have been set forth attempting to identify the cause(s) of the mental health crisis in Mexico. For example, Villarreal and $\mathrm{Yu}$ (2017) have pointed to homicide rates as one of the primary reasons for these increasingly problematic levels of mental health issues. Along with increased violence comes a lack of safety and feelings of susceptibility, which have been linked to depression, agoraphobia, alcohol abuse, and poor mental health (Altman, Gorman, \& Chávez, 2018). Researchers have pointed to the Mexican suicide rate specifically as being linked to this increase in violence and mental health problems (Benjet et al., 2017). Further compounding the crisis is the stigma surrounding seeking help for mental health problems in Mexico, which continues to be a major barrier to the support and treatment of suffering individuals (González, Tarraf, Whitfield, \& Vega, 2010; Harley, 2018). For mental health professionals, medical doctors, researchers, as well as family members of suffering individuals, the current state of adolescent mental health and wellbeing in Mexico constitutes a serious public health concern. 


\subsection{Mental Wellbeing}

One relatively recent approach being used by many countries to assess the impact of mental health problems on its citizens is the study of mental wellbeing (Castellví et al., 2014; Keyes, 2012). Mental wellbeing differs from the concept of mental health in that it looks at more than just the absence of illness, but broadens the focus to include psychological functioning and experience (Ryan \& Deci, 2001). For centuries, the general approach to mental health has been focused on deficits and weaknesses, which has led to our current system of deficits-based diagnosis, assessment, and treatment (DuBois \& Miley, 2014; Hoffman, Rueda, \& Lambert, 2019). As a result, the stigma associated with mental health has negatively impacted help-seeking behaviors (Clement et al., 2015; Eisenberg, Downs, Golberstein, \& Zivin, 2009; Harley, 2018). Fortunately, the fields of social work and positive psychology have been pioneers in working with clients from a strengths-based approach. A "strengths-based" approach focuses on uncovering and emphasizing a client's good qualities to help them use their talents and abilities to achieve positive life changes (Saleebey, 1996). The use of this positive approach is particularly important in the field of mental health because it moves away from inflexible and narrow views of mental health challenges (e.g., labeling) that is reinforced by the traditional deficits-based approach (Rhee, Furlong, Turner, \& Harari, 2001). This change of perspective and approach is important for at least two reasons. First, there is a strong body of research looking at the powerful connection between our mind and our body (e.g., Rosenkranz \& Davidson, 2009; Williams \& Kabat-Zinn, 2011). Framing/treating difficulties from a strengths perspective can assist individuals tap into the power of positive thinking which we know from research is positively associated with wellbeing. Furthermore, a strengths perspective aims to improve self-efficacy, empowering inividuals to see themselves as able to control, manage, and direct their personal health goals (see Grant \& Cadell, 2009; Manthey, Knowles, Asher, \& Wahab, 2011).

One of the measures that has resulted from this movement is the Warwick-Edinburgh Mental Wellbeing Scale (WEMWBS). The WEMWBS is a mental wellbeing assessment that has been adapted for use in many countries and languages, and has consistently performed well on psychometric assessments (López et al., 2013; Stewart-Brown \& Janmohamed, 2008). It has also played a key role in establishing mental wellbeing as an important piece of governments' mental health agendas (Stewart-Brown, 2013). Given that the research on Mexico's mental health is showing a complex combination of difficult problems, using the WEMWBS instrument could be an important method of incorporating a strengths-based approach to our understanding of the current crisis.

\subsection{Health-Related Quality of Life}

Just as the concept of mental wellbeing is altering how we think of mental health, the study of health-related quality of life (HRQOL) is likewise changing how we consider our physical health. In contrast to historically narrow biological markers of health such as disease prevalence and medical conditions, in recent years there has been a greater emphasis placed on patient-reported outcomes via HRQOL (Quittner et al., 2010). One particular instrument that has been cited hundreds of times and used in studies throughout the world is the Pediatric Quality of Life Inventory (PedsQL). This youth-centered HRQOL instrument not only provides an overall look at an individual's HRQOL, but breaks down their total score into physical and psychosocial sub-scale domains. Assessing HRQOL provides researchers and clinicians an interconnected and multifaceted look at the impact of physical, emotional, and social functioning on one's health (Giachello, 1996). For example, measuring HRQOL may be particularly meaningful when working with patients whose emotional and social assets are serving as layers of prevention that blunt the risk or impact of disease (Boehmm \& Kubzansky, 2012; Thurston \& Kubzansky, 2009). Researchers, governments, and health providers in various countries throughout the world - including the United States (Hirsch et al., 2019), Germany (Schlack, Ravens-Sieberer, \& Petermann, 2013), and Mexico (Kantor, Grimes, \& Limbers, 2015) - have begun to assess health more broadly using HRQOL. However, despite its growing use and popularity as a standalone construct, research looking at the connection between HRQOL and other important health constructs is still in its infancy.

\subsection{Mental Wellbeing and Health-Related Quality of Life}

Various global studies support the idea that mental wellbeing is related to HRQOL (Alonso et al., 2018; Cronly et al., 2018). Looking at data from a population survey in Australia, Busija, Tan, and Sanders (2017) found a significant correlation between HRQOL and eight common health conditions, including anxiety, depression, and bipolar disorder. In Italy, Gerino, Rollè, Sechi, and Brustia (2017) found that HRQOL and mental health are negatively impacted by a lack of social support and loneliness among older adults. And in Finland, Saarni et al. (2007) found large losses in HRQOL due to common mental disorders including anxiety and depression at both the individual and population levels. Although the literature exploring the connection between these two health 
constructs is limited, preliminary studies suggest that studying the influence of mental wellbeing on HRQOL may provide health professionals in Mexico with a new mental health tool for understanding negative mental health trends and identifying their connection to physical and psychosocial outcomes.

\subsection{The Present Study}

Given the growing mental health concerns, suicide rates, and related health issues among Mexican youth (Benjet et al., 2017; Villarreal \& Yu, 2017), this study seeks to provide clarity to our understanding of mental wellbeing, health-related quality of life, and their possible connection among a sample of Mexican youth. The purposes of this paper are as follows: 1) Assess the mental wellbeing of a sample of Mexican youth using a strengths-based assessment of mental health (the WEMWBS); 2) Assess their total health-related quality of life using the PedsQL, as well as their physical and psychosocial sub-scores; and 3) examine whether there is a connection between their mental wellbeing and HRQOL. Given the current mental health crisis in Mexico, we hypothesize that participants will have lower levels of mental wellbeing and health-related quality of light, and we hypothesize that mental wellbeing will be positively associated with HRQOL.

\section{Method}

\subsection{Participants and Procedures}

The governing Institutional Review Board approved this study and all its procedures (UTSA Approval Number: 14-241N). The first and second authors of this study collaborated with a research team in Mexico to carry out recruitment and survey administration. Participants were students from a middle school (U.S. equivalent = seventh to ninth grade) in a rural town of Michoacán, Mexico. Two school psychologists led the Mexican research team, which recruited participants and obtained consent. A major part of the financial stability of this community comes from migration to the U.S., which caused some concern among participants' families about personal information and confidentiality when the study was first introduced to them. Therefore, the research team concluded that written consent was unethical, and instead obtained verbal consent by speaking with parents and students about the risks/benefits of participating in the study. Parents and students were told the purpose of the research, specifically that researchers in the U.S. were interested in youth's health and health-related experiences. After this discussion, anyone that wished could withdraw from participation in the study. There were a total of 116 potential participants, and 112 students agreed to participate (54 females, 58 males; mean age $=13, \mathrm{SD}=0.99$ ).

\subsection{Measures}

Participants were asked to complete the Spanish version of the WEMWBS and Pediatric Quality of Life Inventory (PedsQL) as part of a general health survey. The WEMWBS is a 14-item survey measuring mental wellbeing with a 5-point Likert response scale (e.g. "I've been feeling optimistic about the future", "I've been feeling loved"). Individuals' total scores are the sum of their responses, which could range from 14 to 70 (WEMWBS User Guide, 2008). The WEMWBS measures aspects of mental wellbeing that go beyond deficits to include life-satisfaction, mutually beneficial relationships, and positive psychological functioning (WEMWBS User Guide, 2008). The scale was developed by the Scottish government to assess positive mental wellbeing in the United Kingdom (Stewart-Brown \& Janmohamed, 2008). Since then, it has been successfully adapted and translated for use in other countries, specifically Spanish speaking countries such as Spain, Chile, Mexico, and Argentina (Carvajal, Aboaja, \& Rubén, 2015; Castellví et al., 2014; Hoffman, Rueda, \& Lambert, 2019; López et al., 2013). The validity and reliability of the original measure, as well as the Spanish translation, have been rigorously evaluated in many studies and found to be adequate for use among both youth and adults in various countries (López et al., 2013; Stewart-Brown \& Janmohamed, 2008). In Mexico, Hoffman, Rueda, and Lambert (2019) found it to be a psychometrically sound measure of mental wellbeing for Mexican youth.

The PedsQL is a 23-item survey that uses a 5-point Likert response scale and focuses on distinguishing healthy children from children at risk of low HRQOL (e.g. "It is hard for me to run", "I have trouble sleeping"). Individuals' totals are computed by reverse scoring the responses and calculating the mean. The physical health subscale consists strictly of the Physical Functioning section of the survey, while the psychosocial subscale includes the Emotional, Social, and School Functioning sections (Varni, 2012). Studies throughout the world in various languages have shown the PedsQL to be a reliable and valid measure (Varni, Seid, \& Kurtin, 2001; Varni, Seid, \& Rode, 1999).

Control variables for this study were age, gender $(0=$ female, $1=$ male $)$, highest education level obtained by either parent $(0=$ Less than high school $-6=$ doctoral/professional degree $)$, and self-reported overall health $(0=$ poor $4=$ excellent). See Table 1 for a descriptive breakdown of the study variables.

\subsection{Data Analysis}


In order to establish baseline information on the mental wellbeing and health-related quality of life among our sample, descriptive statistics for all variables and bivariate correlations for associations of interest were run using Stata 15 software (StataCorp, 2017). Second, previously established clinical cut off values indicating "at risk" status for HRQOL were used to determine the percentage of students "at risk" (Total Score $=69.71$, Physical Subscale $=72.98$, Psychosocial Subscale $=66.03$; Varni et al., 2003). Lastly, in order to assess the relationship between mental wellbeing and HRQOL, three ordinary least squares (OLS) regression models were run. The first model used the total HRQOL score as the dependent variable, while the subsequent two models used the physical and psychosocial subscales as dependent variables. Control variables included age, gender, parent education, and self-reported overall health.

Table 1. Descriptive Statistics

\begin{tabular}{llll}
\hline Variables & $N$ & $\mathrm{M}(S D)$ & Range \\
\hline Age & 110 & $13.20(0.99)$ & $11-16$ \\
Gender (0=female) & 112 & $0.52(0.50)$ & $0-1$ \\
Parent Education & 104 & $0.73(1.49)$ & $0-6$ \\
Overall Health & 110 & $2.34(0.98)$ & $1-4$ \\
WEMWBS & 93 & $54.47(8.78)$ & $21-70$ \\
PedsQL & 111 & $78.90(12.67)$ & $28.75-100$ \\
$\quad$ Physical & 111 & $84.20(13.15)$ & $18.75-100$ \\
\multicolumn{1}{c}{ Psychosocial } & 111 & $76.06(14.58)$ & $35.42-100$ \\
\hline
\end{tabular}

\section{Results}

Table 1 provides an overview of descriptive statistics for all study variables. Students in our sample came from low SES households, with participant's parents on average having less than a high school education. Students generally considered themselves to be in "good" health, evidenced by an average score of $2.3(\mathrm{SD}=.98)$ on the single-item self-assessment of overall health. The average score on the WEMWBS assessment of mental wellbeing was 54.47, roughly 4 points higher than the average score among the provisional population norm originally established in the UK (WEMWBS User Guide, 2008), and approximately 2-3 points lower than in studies among Spanish speaking adult populations in South America and Spain (Carvajal, Aboaja, \& Alvarado, 2015; Castellví et al., 2014).

Table 2 provides a breakdown of PedsQL scores by "at-risk" status. The average total score was 78.90 (SD = 12.67), with $22.5 \%$ of the sample falling within the at-risk range. The average score on the physical subscale was considerably higher at 84.20 , with slightly fewer $(19.8 \%)$ in the at-risk range. The psychosocial subscale had the lowest average score at $76.06(\mathrm{SD}=14.58)$ and the highest percent of at-risk respondents at $24.3 \%$.

Table 2. PedsQL Breakdown of “At Risk” Status

\begin{tabular}{llll}
\hline Variables & $\mathrm{M}(S D)$ & Range & \% “At Risk” \\
\hline Total & $78.90(12.67)$ & $28.75-100$ & 22.52 \\
Physical & $84.20(13.15)$ & $18.75-100$ & 19.82 \\
Psychosocial & $76.06(14.58)$ & $35.42-100$ & 24.32 \\
\hline
\end{tabular}

Linear regression results predicting quality of life are shown in Table 3. The primary independent variable, mental wellbeing, was a statistically significant predictor for scores on the physical subscale of the PedsQL $(b=0.39, p$ $<.05$ ) as shown in Model 2, but not for the full scale (Model 1) or psychosocial subscale (Model 3). Results also indicate that gender was a statistically significant predictor for total quality of life $(\mathrm{p}<.05)$, and a marginally significant predictor in the subscale models. Also, self-reported overall health was a marginally significant predictor of the physical quality of life subscale, although it was not a significant predictor in the other models. 
Table 3. Linear regressions showing mental well-being predicting total health-related quality of life and health-related quality of life subscales $(\mathrm{N}=86)$

\begin{tabular}{lccc}
\hline & Model 1 (total) & Model 2 (phy) & Model 3 (psysoc) \\
\hline Mental Wellbeing & 0.17 & $0.39^{*}$ & 0.06 \\
Gender & $5.84^{*}$ & $5.13 \dagger$ & $6.37 \dagger$ \\
Age & 0.23 & 1.67 & -0.50 \\
Parental Education & -0.67 & -1.19 & -0.36 \\
Overall Health & 1.44 & $2.67 \dagger$ & 0.71 \\
\hline
\end{tabular}

$\dagger=p<.10 ; *=p<.05$.

\section{Discussion}

The purpose of this study was to examine the relationship between mental wellbeing and HRQOL among youth in rural Mexico. Due to the various mental health issues currently prevalent in Mexico (Benjet et al., 2017; Espinola-Nadurille et al., 2010; Perkins, Wood, Varjas, \& Vanegas, 2016), this study sought to shed light on the relationship between these relatively new constructs of mental and physical health (Castellví et al., 2014; Kantor, Grimes, \& Limbers, 2015; Quittner et al., 2010). We hypothesized that mental wellbeing would be positively correlated with HRQOL.

Our regression analyses show that mental wellbeing scores significantly predicted scores on the physical subscale of the PedsQL. This finding is supported by previous research on physical activity and mental health in adolescents (Biddle \& Asare, 2011; Snyder et al., 2010). Biddle, Ciaccioni, Thomas, and Vergeer (2018) reviewed multiple meta-analyses and concluded that a strong causal relationship exists between physical activity and cognitive functioning. Additionally, they concluded a partial causal relationship exists between depression and physical inactivity for youth. Although we can make no claims of causality, there is evidence from this study suggesting that alternative methods of measuring mental and physical health (i.e., Quality of Life and Mental Wellbeing) demonstrate a similar relationship among our sample of Mexican youth.

Mental wellbeing was not found to be associated with either the full PedsQL scale or its psychosocial subscale. This was somewhat surprising given the theoretical overlap between mental wellbeing and health-related quality of life, and the fact that both scales measured components of mental and emotional health. Indeed, prior research on these constructs in the US and Mexico led us to believe there would be a significant correlation among them (Benjet et al., 2016; Nelson et al., 2014). The lack of a relationship may be partially explained by the unique aspects of our population's environment, society, and culture. For example, many families in Michoacán live in a low SES rural environment, often struggling to consistently have their basic needs met. This may explain the higher number of "at risk" scores on the PedsQL within our sample. By way of comparison, Nelson et al. (2014) studied a high-risk population of youth in a large residential foster care treatment center in the U.S., and only $13 \%$ were at risk on the physical subscale of the PedsQL, compared with almost $20 \%$ in our sample. The percentage of at-risk youth in the US study was also lower across both the psychosocial subcategory (19.7\% vs. $24.3 \%)$ and total score (17.9\% vs. $22.5 \%$ ). Consistent with Maslow's Theory of Human Motivation (Maslow, 1943) there could be a greater focus on meeting basic needs rather than achieving social and mental wellbeing within our sample. Furthermore, as Villarreal and Yu (2017) have noted, the drug trafficking and homicide rates in Mexico have made a substantial impact on the social and mental wellbeing of communities. Increased fear, anxiety, and exposure to violence may be impacting mental wellbeing and quality of life among our sample in unmeasured and unforeseen ways. Future studies looking at mental wellbeing and quality of life among Mexican youth should include information on substance use and exposure to violence in an effort to more clearly understand the relationship between these constructs. From a practical standpoint, if future studies suggest that our unexpected findings might be tied to the youth's challenging environment, the use of positive, strength-based measures such as mental wellbeing (instead of mental illness) and health-related quality of life (instead of sickness) could be quite important. Supportive, positively-framed measures that highlight strengths instead of weaknesses could provide an empowering lens through which to look at their lives. Indeed, substantial literature recommends the use of encouragement and hope when working with individuals (Main \& Boughner, 2011; Wong, 2015).

Surprisingly, parental education, which was used as a proxy for socioeconomic status in this study, was not significant in any of the models. Socioeconomic status often plays a key role in individuals' health behaviors (Chen \& Miller, 2013; Milas, Klaric, Malnar, Šupe-Domic, \& Slavich, 2019; Nandi, Glymour, \& Subramanian, 2014). It 
is likely that the homogeneous economic status of families from which our sample was drawn is the explanation for this unexpected result. Gender, on the other hand, was a significant predictor for total scores on the PedsQL, and a marginally significant predictor in both subscales, suggesting that being female was predictive of poorer HRQOL. This is consistent with previous research on the topic of mental health in Mexico (Nuñez et al., 2016), specifically concluding that females may be more negatively impacted by rigid societal definitions of gender roles (Fragoso \& Kashubeck, 2000; Nuñez et al., 2016; Piña-Watson, Castillo, Ojeda, \& Rodriguez, 2013; Watkins et al., 2013) as well as tend to report more internalizing as opposed to externalizing behaviors. The gender differences could also be due to the unique cultural expectations among adolescent males and females, which are particularly salient in rural migratory communities of Central Mexico (Hoffman, 2014). These include financial expectations for young men in the form of migration (Kandel \& Massey, 2002), as well as norms surrounding dating violence and high-risk sexual behavior, where communities tend to be more lenient towards males than females (Ayers, Marsiglia, Hoffman, Urbaeva, \& Booth, 2012; Rueda, Hoffman, \& Grytza, 2019).

\subsection{Limitations}

One of the limitations of this study was the cross-sectional nature of the research design. We outlined and assessed how mental wellbeing could impact quality of life, but it is possible that quality of life is actually the driving force behind mental wellbeing. Future studies using longitudinal data could more fully flush out the relationship between these two constructs. Also, due to the limited amount of research that has looked at these contructs among youth populations in Mexico, future studies should consider in-depth qualitative interviews that focus on not only the nuances of mental wellbeing and health-related quality of life, but also their interconnectiveness. A second limitation is that our sampling methodology precluded youth participation among those who had dropped out of school, work instead of go to school, or otherwise were not attending school. Due to our non-random sampling approach, these findings should not be generalized to other youth populations or assumed to represent all youth in rural settings. Replication studies are needed to verify if similar results are present in other youth populations throughout the country. Despite its limitations, this study does provide a first-look at mental wellbeing and health-related quality of life among an understudied population of youth in Central Mexico.

\subsection{Conclusions}

If replicated, our results may have important implications for health professionals, social workers, researchers, policy makers, and other individuals living in Mexico. On the micro-level, our findings can be useful to address clinical needs of the individual. For example, the direct link between physical activity and mental wellbeing supports treatment interventions for improving physical health. Implications on the mezzo-level could include family therapy and similar small-group supports that take into consideration the unique social and physical environment in which youth in Michoacán live, which may be impacting youths' psychosocial quality of life. Macro-level implications of this study suggest a continued focus on community programs to improve physical and mental wellbeing of youth. For example, solid physical education programs where students set health goals and strive to achieve them would be an important asset to youth in a time when physical education has become less of a priority in public schooling. In addition, supporting or improving community healthcare systems could be very impactful as chronic illness has been linked to low HRQOL for adolescents and adults (Busija, Tan, \& Sanders, 2017). Establishing relationships between healthcare centers and youth in the community is particularly important in rural areas of Central Mexico where research suggests that healthcare providers often struggle to meet youth-specific needs and fail to teach about preventative care in their communities (Hoffman, Rueda, \& Beasley, 2019). Providing supports early in life is the most logical approach to preventing future problems with chronic illnesses and low HRQOL. For all levels of work, we suggest the Ecological Systems theory be used to guide this important effort because it accounts for culture, community, and societal attributes of human behavior (Bronfenbrenner, 1989), which aligns with the goals and purposes of measuring HRQOL. In brief, we encourage continued research among Mexican youth in rural, underserved areas of Central Mexico such as Michoacán in order to further support strengths-based approaches for improving both their mental wellbeing and quality of life.

\section{Competing Interests Statement}

The authors declare that there are no competing or potential conflicts of interest.

\section{References}

Aknin, L. B., Barrington-Leigh, C. P., Dunn, E. W., Helliwell, J. F., Burns, J., Biswas-Diener, R., ... \& Norton, M. I. (2013). Prosocial spending and well-being: Cross-cultural evidence for a psychological universal. Journal of Personality and Social Psychology, 104(4), 635. https://doi.org/10.1037/a0031578

Albores-Gallo, L., Sauceda-García, J., Ruiz-Velasco, S., \& Roque-Santiago, E. (2011). El acoso escolar (bullying) 
y su asociación con trastornos psiquiátricos en una muestra de escolares en México (Spanish). Salud Pública De México, 53(3), 220-227.

Alonso, J., Saha, S., Lim, C. C. W., Aguilar-Gaxiola, S., Al-Hamzawi, A., Benjet, C., .. \& McGrath, J. J. (2018). The association between psychotic experiences and health-related quality of life: A cross-national analysis based on world mental health surveys. Schizophrenia Research. https://doi.org/10.1016/j.schres.2018.04.044

Altman, C. E., Gorman, B. K., \& Chávez, S. (2018). Exposure to violence, coping strategies, and diagnosed mental health problems among adults in a migrant-sending community in central mexico. Population Research and Policy Review, 37(2), 229-260. https://doi.org/10.1007/s11113-018-9460-х

Ayers, S. L., Marsiglia, F. L., Hoffman, S., Urbaeva, J., \& Booth, J. (2012). Mexican adolescents' risky sexual behavior and migration intentions. International Journal of Migration, Health, and Social Care, 8(2), 56-71. https://doi.org/10.1108/17479891211249997

Benjet, C., Borges, G., Méndez, E., Albor, Y., Casanova, L., Orozco, R., Curiel, T., Fleiz, C., \& Medina-Mora, M. (2016). Eight-year incidence of psychiatric disorders and service use from adolescence to early adulthood: Longitudinal follow-up of the Mexican adolescent mental health survey. European Child \& Adolescent Psychiatry, 25(2), 163-173. https://doi.org/10.1007/s00787-015-0721-5

Benjet, C., Menendez, D., Albor, Y., Borges, G., Orozco, R., \& Medina-Mora, M. (2017). Adolescent predictors of incidence and persistence of suicide-related outcomes in young adulthood: A longitudinal study of mexican youth. Suicide and Life-Threatening Behavior. https://doi.org/10.1111/sltb.12397

Biddle, S. J., \& Asare, M. (2011). Physical activity and mental health in children and adolescents: A review of reviews. British Journal of Sports Medicine, 45(11), 886-895. https://doi.org/10.1136/bjsports-2011-090185

Biddle, S. J., Ciaccioni, S., Thomas, G., \& Vergeer, I. (2018). Physical activity and mental health in children and adolescents: An updated review of reviews and an analysis of causality. Psychology of Sport and Exercise, https://doi.org/10.1016/j.psychsport.2018.08.011

Boehm, J. K., \& Kubzansky, L. D. (2012). The heart's content: the association between positive psychological well-being and cardiovascular health. Psychological Bulletin, 138(4), 655. https://doi.org/10.1037/a0027448

Borges, G., Wang, P., Medina-Mora, M., Lara, C., \& Chiu, W. (2007). Delay of first treatment of mental and substance use disorders in Mexico. American Journal of Public Health, 97(9), 1638-1643. https://doi.org/10.2105/AJPH.2006.090985

Bronfenbrenner, U. (1989). Ecological systems theory. Annals of Child Development, 6, 187-249.

Busija, L., Tan, J., \& Sanders, K. M. (2017). Associations between illness duration and health-related quality of life in specified mental and physical chronic health conditions: Results from a population-based survey. Quality of Life Research: An International Journal of Quality of Life Aspects of Treatment, Care \& Rehabilitation, 26(10), 2671-2681. https://doi.org/10.1007/s11136-017-1592-7

Carvajal, D., Aboaja, A., \& Rubén, A. (2015). Validación de la escala de bienestar mental de Warwick- Edinburgo, en Chile. Revista de Salud Pública, 19(1), 13-21. https://doi.org/10.5354/0719-5281.2015.36349

Castellvi, P., Forero, C. G., Codony, M., Vilagut, G., Brugulat, P., Medina, A., ... Alonso, J. (2014). The Spanish Version of the Warwick-Edinburgh Mental Well-Being Scale (WEMWBS) is Valid for Use in the General Population. Quality of Life Research, 23(3), 857-68. https://doi.org/10.1007/s11136-013-0513-7

Chen, E., \& Miller, G. E. (2013). Socioeconomic status and health: Mediating and moderating factors. Annual Review of Clinical Psychology, 9, 723-749. https://doi.org/10.1146/annurev-clinpsy-050212-185634

Clement, S., Schauman, O., Graham, T., Maggioni, F., Evans-Lacko, S., Bezborodovs, N., Morgan, C., Rüsch, N., Brown, J.S.L., Thornicroft, G. (2015). What is the impact of mental health-related stigma on help-seeking? A systematic review of quantitative and qualitative studies. Psychological Medicine, 45(1), 11-27. https://doi.org/10.1017/S0033291714000129

Cronly, J., Duff, A., Riekert, K., Horgan, A., Lehane, E., Perry, I., ... \& Savage, E. (2018). Positive mental health and wellbeing in adults with cystic fibrosis: A cross sectional study. Journal of Psychosomatic Research. https://doi.org/10.1016/j.jpsychores.2018.11.016

Derdikman-Eiron, R., Indredavik, M. S., Bratberg, G. H., Taraldsen, G., Bakken, I. J., \& Colton, M. (2011). Gender differences in subjective well-being, self-esteem and psychosocial functioning in adolescents with symptoms of anxiety and depression: Findings from the Nord-Trøndelag health study. Scandinavian Journal 
of Psychology, 52(3), 261-267. https://doi.org/10.1111/j.1467-9450.2010.00859.x

DuBois, B. L., \& Miley, K. K. (2014). Social work: An empowering profession (8th ed.). New York: Pearson. ISBN: 9780205848942

Eisenberg, D., Downs, M. F., Golberstein, E., \& Zivin, K. (2009). Stigma and help seeking for mental health among college students. Medical Care Research and Review, 66(5), 522-541. https://doi.org/10.1177/1077558709335173

Espinola-Nadurille, M., Huicochea, I. V., Raviola, G., Ramirez-Bermudez, J., \& Kutcher, S. (2010). Child and adolescent mental health services in Mexico. Psychiatric Services, 61, 443-445. https://doi.org/10.1176/appi.ps.61.5.443

Fischer, K., van der Bom, J. G., Mauser-Bunschoten, E., Roosendaal, G., Prejs, R., de Kleijn, P., ... \& van, D. B. (2002). The effects of postponing prophylactic treatment on long-term outcome in patients with severe hemophilia. Blood, 99(7), 2337-2341. https://doi.org/10.1182/blood.V99.7.2337

Fox, K. R. (1999). The influence of physical activity on mental well-being. Public Health Nutrition, 2(3a), 411-418. https://doi.org/10.1017/S1368980099000567

Fragoso, J. M., \& Kashubeck, S. (2000). Machismo, gender role conflict, and mental health in Mexican American men. Psychology of Men \& Masculinity, 1(2), 87. https://doi.org/10.1037/1524-9220.1.2.87

Giachello, A. L. (1996). Health outcomes research on Hispanics/Latinos. Journal of Medical Systems, 20(5), 235-254. https://doi.org/10.1007/BF02257038

Gerino, E., Rollè, L., Sechi, C., \& Brustia, P. (2017). Loneliness, resilience, mental health, and quality of life in old age: A structural equation model. Frontiers in Psychology, 8. https://doi.org/10.3389/fpsyg.2017.02003

González, H. M., Tarraf, W., Whitfield, K. E., \& Vega, W. A. (2010). The epidemiology of major depression and ethnicity in the United States. Journal of Psychiatric Research, 44(15), 1043-1051. https://doi.org/10.3389/fpsyg.2017.02003

Grant, J. G., \& Cadell, S. (2009). Power, pathological worldviews, and the strengths perspective in social work. Families in Society: The Journal of Contemporary Social Services, 90(4), 425-430. https://doi.org/10.1606/1044-3894.3921

Harley, D. A. (2018). People with disabilities and mental health disorders in Mexico: Rights and practices. In D. A. Harley, N. A. Ysasi, M. L. Bishop \& A. R. Fleming (Eds.), Disability and vocational rehabilitation in rural settings: Challenges to service delivery (pp. 367-381). Cham: Springer International Publishing. https://doi.org/10.1007/978-3-319-64786-9_20

Hirsch, J. K., Sirois, F. M., Visser, P. L., Brooks, B. D., Kohls, N., Offenbächer, M., \& Toussaint, L. (2019). Perceived stigma and health-related quality of life in the working uninsured: Does thwarted belongingness play a role? Stigma and Health, 4(1), 1-10. https://doi.org/10.1007/978-3-319-64786-9_20

Hoffman, S. (2014). Suicidal ideation and migration aspirations among youth in Central Mexico. Global Journal of Health Science, 6(1), 92-98. https://doi.org/10.5539/gjhs.v6n1p92

Hoffman, S., Rueda, H. A., \& Lambert, M. C. (2019). Confirmatory factor analysis of the Warwick-Edinburgh Mental Wellbeing Scale among youth in Mexico. International Social Work, 62(1), 309-315. https://doi.org/10.1177/0020872817727576

Kandel, W., \& Massey, D. S. (2002). The culture of Mexican migration: A theoretical and empirical analysis. Social Forces, 80, 981-1004. https://doi.org/10.1353/sof.2002.0009

Kantor, R. M., Grimes, G. R., \& Limbers, C. A. (2015). Physical activity, sedentary behaviors, and health-related quality of life in rural Hispanic youth. Translational Issues in Psychological Science, 1(3), 239-249. https://doi.org/10.1037/tps0000030

Keyes, C. L. M. (2012). Mental well-being: International contributions to the study of positive mental health Springer Netherlands. Retrieved from https://books.google.com/books?id=_Yv5_LMmPL8C

Kieling, C., Baker-Henningham, H., Belfer, M., Conti, G.,Ertem, I, Omigbodun, O, Rohde, L. A., Srinath, S., Ulkuer, N., \& Rahman, A. (2011). Child and adolescent mental health worldwide: Evidence for action. Lancet, 378, 155-1525. https://doi.org/10.1016/S0140-6736(11)60827-1

Kobau, R., Cui, W., \& Zack, M. M. (2017). Adults with an epilepsy history fare significantly worse on positive mental and physical health than adults with other common chronic conditions-Estimates from the 2010 
national health interview survey and patient reported outcome measurement system (PROMIS) global health scale. Epilepsy \& Behavior, 72, 182-184. https://doi.org/10.1016/j.yebeh.2017.04.047

Lente, E., Barry, M. M., Molcho, M., Morgan, K., Watson, D., Harrington, J., \& McGee, H. (2012). Measuring population mental health and social well-being. International Journal of Public Health, 57(2), 421-430. https://doi.org/10.1007/s00038-011-0317-x

Lopez, M. A., Gabilondo, A., Codony, M., Garcia-Forero, C., Vilagut, G., Castellvi, P., ... \& Alonso, J. (2013). Adaptation into Spanish of the Warwick-Edinburgh Mental Well-Being Scale (WEMWBS) and Preliminary Validation in a Student Sample. Quality of Life Research, 22(5), 1099-104. https://doi.org/10.1007/s11136-012-0238-z

Main, F. O., \& Boughner, S. R. (2011). Encouragement and actionable hope: The source of Adler's clinical agency. The Journal of Individual Psychology, 67(3). 269-291.

Manthey, T. J., Knowles, B., Asher, D., \& Wahab, S. (2011). Strengths-based practice and motivational interviewing. Advances in Social Work, 12(2), 126-151. https://doi.org/10.18060/959

Maslow, A. H. (1943). A theory of human motivation. Psychological Review, 50(4), 370-396. https://doi.org/10.1037/h0054346

Medina-Mora, M., Borges, G., Benjet, C., Lara, C., \& Berglund, P. (2007). Psychiatric disorders in Mexico: Lifetime prevalence in a nationally representative sample. The British Journal of Psychiatry, 190, 521-528. https://doi.org/10.1192/bjp.bp.106.025841

Milas, G., Klaric, I. M., Malnar, A., Šupe-Domic, D., \& Slavich, G. M. (2019). Socioeconomic status, social-cultural values, life stress, and health behaviors in a national sample of adolescents. Stress \& Health: Journal of the International Society for the Investigation of Stress, 35(2), 217-224. https://doi.org/10.1002/smi.2854

Nandi, A., Glymour, M. M., \& Subramanian, S. V. (2014). Association among socioeconomic status, health behaviors, and all-cause mortality in the United States. Epidemiology, 25(2), 170-177. https://doi.org/10.1097/EDE.0000000000000038

Nelson, T. D., Kidwell, K. M., Hoffman, S., Trout, A. L., Epstein, M. H., \& Thompson, R. W. (2014). Health-related quality of life among adolescents in residential care: Description and correlates. American Journal of Orthopsychiatry, 84(3), 226. https://doi.org/10.1037/h0099812

Nuñez, A., González, P., Talavera, G. A., Sanchez-Johnsen, L., Roesch, S. C., Davis, S. M., Arguelles, W., Womack, V. Y., Ostrovsky, N. W., Ojeda, L. (2016). Machismo, marianismo, and negative cognitive-emotional factors: Findings from the Hispanic community health study/study of Latinos sociocultural ancillary study. Journal of Latina/O Psychology, 4(4), 202. https://doi.org/10.1037/lat0000050

Organisation for Economic Co-operation and Development (OECD). (2010). Higher education in regional and city development: State of Veracruz, Mexico, Higher Education in Regional and City Development. OECD Publishing.

Parchment, T. M., Small, L., Osuji, H., McKay, M., \& Bhana, A. (2016). Familial and contextual influences on children's prosocial behavior: South African caregivers as adult protective shields in enhancing child mental health. Global Social Welfare, 3(1), 1-10. https://doi.org/10.1007/s40609-016-0042-8

Park, N. (2004). The role of subjective well-being in positive youth development. The Annals of the American Academy of Political and Social Science, 591(1), 25-39. https://doi.org/10.1177/0002716203260078

Piña-Watson, B., Castillo, L. G., Ojeda, L., \& Rodriguez, K. M. (2013). Parent conflict as a mediator between marianismo beliefs and depressive symptoms for Mexican American college women. Journal of American College Health, 61(8), 491-496. https://doi.org/10.1080/07448481.2013.838567

Perkins, C., Wood, L., Varjas, K., \& Vanegas, G. (2016). Psychological well-being of children and youth in Mexico. In B. K. Nastasi \& A. P. Borja (Eds.), International handbook of psychological well-being in children and adolescents: bridging the gaps between theory, research, and practice (pp. 115-135). New York, NY: Springer New York. https://doi.org/10.1007/978-1-4939-2833-0_8

Quittner, A. L., Schechter, M. S., Rasouliyan, L., Haselkorn, T., Pasta, D. J., \& Wagener, J. S. (2010). Impact of socioeconomic status, race, and ethnicity on quality of life in patients with cystic fibrosis in the United States. CHEST Journal, 137, 642-650. https://doi.org/10.1378/chest.09-0345 
Raposa, E. B., Laws, H. B., \& Ansell, E. B. (2016). Prosocial Behavior Mitigates the Negative Effects of Stress in Everyday Life. Clinical Psychological Science, 4(4), 691-698. https://doi.org/10.1177/2167702615611073

Rhee, S., Furlong, M. J., Turner, J. A., \& Harari, I. (2001). Integrating strength-based perspectives in psychoeducational evaluations. The California School Psychologist, 6(1), 5-17. https://doi.org/10.1007/BF03340879

Rosenkranz, M. A., \& Davidson, R. J. (2009). Affective neural circuitry and mind-body influences in asthma. Neurolmage, 47(3), 972-980. https://doi.org/10.1016/j.neuroimage.2009.05.042

Rueda, H. A., Hoffman, S. H., \& Grytza, K. (2019). Proving their love: Violence and gender norms in descriptions of relationships among rural Mexican adolescents. Children and Youth Services Review, 105. https://doi.org/10.1016/j.childyouth.2019.104424

Ryan, R. M., \& Deci, E. L. (2001). On happiness and human potentials: A review of research on hedonic and eudaimonic well-being. Annual Review of Psychology, 52, 141-166. https://doi.org/10.1146/annurev.psych.52.1.141

Saarni, S. I., Suvisaari, J., Sintonen, H., Pirkola, S., Koskinen, S., Aromaa, A., \& Lönnqvist, J. (2007). Impact of psychiatric disorders on health-related quality of life: General population survey. The British Journal of Psychiatry, 190(4), 326-332. https://doi.org/10.1192/bjp.bp.106.025106

Saleebey, D. (1996). The strengths perspective in social work practice: Extensions and cautions. Social Work, 41(3), 296-305. Retrieved from https://www-lib-byu-edu.erl.lib.byu.edu/cgibin/remoteauth.pl?url=http://search.ebscohost.com.erl.lib.byu.e $\mathrm{du} /$ login.aspx?direct $=$ true $\& \mathrm{db}=$ psyh\&AN=1996-03967-006\&site=ehost-live \&scope $=$ site

Salvini, M., Gall, S., Müller, I., Walter, C., Randt, R., Steinmann, P., .. \& \& Gerber, M. (2018). Physical activity and health-related quality of life among schoolchildren from disadvantaged neighbourhoods in Port Elizabeth, South Africa. Quality of Life Research: An International Journal of Quality of Life Aspects of Treatment, Care \& Rehabilitation, 27(1), 205-216. https://doi.org/10.1007/s11136-017-1707-1

Schlack, R., Ravens-Sieberer, U., \& Petermann, F. (2013). Psychological problems, protective factors and health-related quality of life in youth affected by violence: The burden of the multiply victimised. Journal of Adolescence, 36(3), 587-601. https://doi.org/10.1016/j.adolescence.2013.03.006

Snyder, A. R., Martinez, J. C., Bay, R. C., Parsons, J. T., Sauers, E. L., \& McLeod, T. C. V. (2010). Health-related quality of life differs between adolescent athletes and adolescent nonathletes. Journal of Sport Rehabilitation, 19(3), 237-248. https://doi.org/10.1123/jsr.19.3.237

StataCorp. (2017). Stat Statistical Software: Release 15. College Station, TX: StataCorp LP.

Stewart-Brown, S. (2013). The warwick-edinburgh mental well-being scale (WEMWBS): Performance in different cultural and geographical groups. In C. L. M. Keyes (Ed.), Mental well-being: International contributions to the study of positive mental health (pp. 133-150). Dordrecht: Springer Netherlands. https://doi.org/10.1007/978-94-007-5195-8_7

Teh, H. C., Archer, J. A., Chang, W., \& Chen, S. H. A. (2015). Mental well-being mediates the relationship between perceived stress and perceived health. Stress and Health: Journal of the International Society for the Investigation of Stress, 31(1), 71-77. https://doi.org/10.1002/smi.2510

Thurston, R. C., \& Kubzansky, L. D. (2009). Women, loneliness, and incident coronary heart disease. Psychosomatic Medicine, 71(8), 836. https://doi.org/10.1097/PSY.0b013e3181b40efc

Tourani, S., Behzadifar, M., Martini, M., Aryankhesal, A., Taheri Mirghaed, M., Salemi, M., ... \& Bragazzi, N. L. (2018). Health-related quality of life among healthy elderly Iranians: A systematic review and meta-analysis of the literature. Health and Quality of Life Outcomes, 16. https://doi.org/10.1186/s12955-018-0845-7

Varni, J. W. (2012). About the model. The PedsQL ${ }^{\mathrm{TM}}$ Measurement Model for the Pediatric Quality of Life Inventory. http://www.pedsql.org/about_pedsql.html. Accessed Feb 1, 2019.

Varni, J. W., Burwinkle, T. M., Seid, M., \& Skarr, D. (2003). The PedsQLTM 4.0 as a pediatric population health measure: Feasibility, reliability, and validity. Ambulatory Pediatrics, 3, 329-341. https://doi.org/10.1367/1539-4409(2003)003\%3C0329:TPAAPP\%3E2.0.CO;2

Varni, J., Seid, M., \& Kurtin, P. (2001). PedsQL ${ }^{\text {тм }}$ 4.0: Reliability and Validity of the Pediatric Quality of Life Inventory ${ }^{\mathrm{TM}}$ Version 4.0 Generic Core Scales in Healthy and Patient Populations. Medical Care, 39(8), 
800-812. https://doi.org/10.1097/00005650-200108000-00006

Varni, J., Seid, M., \& Rode, C. (1999). The PedsQLTM: Measurement Model for the Pediatric Quality of Life Inventory. Medical Care, 37(2), 126-139. https://doi.org/10.1097/00005650-199902000-00003

Villarreal, A., \& Yu, W. (2017). Crime, fear, and mental health in Mexico. Criminology: An Interdisciplinary Journal, 55(4), 779-805. https://doi.org/10.1111/1745-9125.12150

Watkins, L. L., Koch, G. G., Sherwood, A., Blumenthal, J. A., Davidson, J. R., O'Connor, C., \& Sketch Jr, M. H. (2013). Association of anxiety and depression with all-cause mortality in individuals with coronary heart disease. Journal of the American Heart Association, 2(2), e000068. https://doi.org/10.1161/JAHA.112.000068

Williams, J. M. G., \& Kabat-Zinn, J. (2011) Mindfulness: diverse perspectives on its meaning, origins, and multiple applications at the intersection of science and dharma. Contemporary Buddhism, 12(1), 1-18. https://doi.org/10.1080/14639947.2011.564811

Wong, Y. J. (2015). The psychology of encouragement: Theory, research, and applications. The Counseling Psychologist, 43(2). 175-216. https://doi.org/10.1177/0011000014545091

\section{Copyrights}

Copyright for this article is retained by the author(s), with first publication rights granted to the journal.

This is an open-access article distributed under the terms and conditions of the Creative Commons Attribution license (http://creativecommons.org/licenses/by/4.0/). 